\title{
The Impact of German Energy Policy on Household Energy Use
}

Eoin Grealis, Annika-Kathrin Musch and Henrike Rau

Abstract This chapter reviews current energy policy and civil society efforts to achieve the targets set out for Germany's Energiewende (Energy Transition), with a specific focus on their impact on household energy use. The existing energy governance structure, conflicting energy policy commitments, and the emergence of public resistance to renewable infrastructure are identified as significant challenges for national-level policy. At the household level, the dominance of efficiency and smart choice solutions and the pressure to maintain traditional patterns of consumption are identified as key limiting factors in an effort to deliver real reductions in household energy use.

Keywords Energy policy - Household energy use - Energy infrastructure $\cdot$ Germany $\cdot$ Energy transition

E. Grealis $(\bowtie) \cdot$ A.-K. Musch $\cdot$ H. Rau

LMU Munich, Munich, Germany

A.-K. Musch

e-mail: a.musch@lmu.de

H. Rau

e-mail: Henrike.rau@lmu.de

(C) The Author(s) 2019

F. Fahy et al. (eds.), Energy Demand Challenges in Europe, https://doi.org/10.1007/978-3-030-20339-9_3 


\section{INTRODUCTION}

Germany has committed to a number of targets in order to achieve a successful Energiewende (energy turn), the transition to a sustainable energy system. These include $60 \%$ of total energy demand being supplied from renewable resources and a total greenhouse gas emission (GHG) reduction target of $80-95 \%$ of 1990 levels by 2050 (BMWi 2015). While the country has recently made progress in some areas, particularly with the deployment of renewable energy capacity in the electricity sector, current forecasts suggest that Germany will miss its interim GHG emissions target of a $40 \%$ reduction on 1990 levels by 2020. Instead, the Federal Ministry projects a reduction of $32 \%$ over the same period. Additionally, recent policy commitments to a faster phasing out of nuclear power have limited nuclear's capacity as a non-carbon-intensive 'bridging technology' (albeit one that presents other sustainability risks) until such time when technological and infrastructural solutions are in place to ensure the stability of supply with large-scale renewable deployment. In order to achieve its stated emissions targets, Germany must reduce annual GHG emissions at a consistent rate of $3.5 \%$ per annum on current levels for the next 30 years. Considering that the 30 -year historical average is a reduction of $1.2 \%$, and the 10-year average just $0.8 \%$, this presents a significant challenge (EEA 2019), which must be addressed by several sectors, including households.

\section{Socio-Material Dynamics of Household ENERGy UsE IN GERMANY}

Households account for approximately a quarter of total energy demand in Germany, ranking third behind the industrial (47\%) and services sectors (26\%) in 2017 (BDEW 2018). Total residential energy demand is dominated by space $(68 \%)$ and water $(14 \%)$ heating requirements, with the remaining energy use accounted for by lighting and appliances $(8 \%)$, cooking $(6 \%)$ and other uses $(4 \%)$ (Eurostat 2018a). Household energy consumption is still dominated by fossil fuels, including oil- and gas-fired heating systems (gas $37 \%$, oil $22 \%$ ), with electricity $\left(21 \%^{1}\right.$ ),

\footnotetext{
${ }^{1}$ Of $20.8 \%$, $12.9 \%$ was generated from fossil fuels sources in 2017 with the remaining $7.9 \%$ generated from renewable sources (Fraunhofer Institute 2018).
} 
renewables $(11 \%)$, derived heat $(8 \%)$ and solid fuels $(1 \%)$ providing the rest (Eurostat 2018b). Germany ranks 6th out of the EU28 in terms of per capita electricity consumption, with the International Energy Agency reporting an average consumption of just over $7000 \mathrm{kWh}$ per annum in 2014 (IEA 2014).

Dwelling location, type, size, tenure and household composition are significant factors in the determination of household energy use. At $40 \%$, Germany has the third highest proportion of single-person households in the EU (Eurostat 2019a), which translates into a comparatively higher average per capita living space. With a predominantly clustered pattern of settlement, $77 \%$ of the $82.9 \mathrm{~m}$ population live in either an urban or predominantly urban location, with just $23 \%$ classified as living in rural areas (Eurostat 2019b). Consequently, apartment and other shared dwellings serve the majority (approx. 60\%) of German households, with the remaining residences consisting of a mixture of detached $(26 \%)$ and semi-detached and terraced housing (Eurostat 2019b). The high instance of apartment living has meant that shared private spaces and services are widespread and culturally acceptable. For example, shared laundering facilities in the basements of apartment complexes are a common occurrence while utility costs associated with common areas are often divided among residents.

With regard to tenure, lifelong tenancy is a common and widely accepted cultural phenomenon in Germany. Germany has the highest rate of household tenancy $(49 \%)$ and the lowest rate of home ownership (51\%) in the EU (although higher than Switzerland) (Eurostat 2019c). This can be attributed to a mix of both historical redevelopment (inclusion of the private building sector in post-war social housing schemes) and comparatively strong tenancy rights. However, high tenancy rates have the potential to reduce the market for sustainable investments if tenants do not receive a share of the benefits, both in terms of energy saving measures (e.g. retrofitting) and renewable generation (e.g. solar). This has been recognised under recent amendments to the Renewable Energy Act (2014), which ensures that tenants and landlords both receive a share of return from sustainable energy investments through a subsidy paid for domestic electricity production (BMJV 2018). 


\section{Energy Policy in Germany}

Energy policy at the federal level in Germany is dominated by supply-side and infrastructural legislative measures, largely influenced by both its implementation obligations under EU directives ${ }^{2}$ and national policy documents. Technical regulations derive primarily from the Energy Industry Act governing grid network charges, transmission, reserve, access and default supply, while regulations governing the transition to less carbon-intensive energy supply stem primarily from the Renewable Energy Sources Act (BMJV 2018). The latter broadly promotes the advancement of technological and market solutions that will enable Germany to reach a target of $80 \%$ of power generation from renewable resources by 2050 .

Recently, Germany has made significant progress on the penetration of renewables, particularly in the electricity sector, with renewables accounting for 38\% of net public power supply in 2017 (Fraunhofer Institute 2018). However, the accident at the Fukushima nuclear power plant in 2011, and subsequent political developments in Germany (particularly in the state of Baden-Württemberg ${ }^{3}$ ), have had a significant impact on Germany's nuclear energy policy, with the Federal government removing nuclear power as a defined 'bridging technology' towards achieving the Energiewende and legislating for a decommissioning timeline for most nuclear power plants by 2022 (BMJV 2018). As a result, increased levels of renewables may now result in a corresponding increase in the use of fossil fuels for electricity production (Renn and Marshall 2016). Consequently, attention among Energiewende campaigners and advocates has shifted towards decommissioning coal-related technology and infrastructure, as exemplified by the Ende Gelände movement that seeks to stop the use of coal.

In addition to the technical barriers to renewable expansion, there is also mounting public resistance to Energiewende projects, most notably in relation to wind farm developments and the construction and

\footnotetext{
${ }^{2}$ Flowing from both the EU Climate and Energy Package (governing the 20/20/20 targets) and the European Climate and Energy Framework (outlining targets for 2030) policy frameworks.

${ }^{3}$ In 2011 the Green Party won the State elections in Baden-Württemberg, partly because of its ability to capitalise on the Fukushima incident to promote proposals for a rapid 'energy turn' towards renewables.
} 
upgrading of power lines. In 2014, the German government, responding to increasing public resistance to the implementation of local energy transition projects and the required upgrading and expansion of the electricity grid, agreed to slow down the expansion of renewable energy projects and limit further expansion to 'development corridors' as well as revising the aims of the Renewable Energy Act (2014). While the primary policy focus had up to this point been on the accelerated decarbonisation of energy used to create electricity, recent developments are beginning to shift attention towards demand-side policies, together with associated ordinances such as the law on the eco-design of energy-related products (BMJV 2017).

While overarching policies are developed at a Federal level, much of the practical actions required to deliver a successful Energiewende fall on local municipalities and civil society. The highly devolved nature of local administration means that local municipalities are primarily responsible for either taking direct action (in terms of their own energy use/supply) or indirect action such as providing the necessary conditions for private/semiprivate sustainable investments or supporting civil society actions aimed at lowering energy consumption. The capacity and extent of municipalities' engagement in such actions is a result of the available resources (budgetary and physical), the extent of devolved administrative competence, and the level of political prioritisation, which may differ considerably both across and within each State/Bundesland. As a consequence, the Energiewende is likely to progress at different rates across Germany. In fact, in some instances past policy both at the Federal and State levels has clearly undermined renewable energy development with overly prescriptive development restrictions, resulting in an effective ban of particular types of generation in certain areas (Naßmacher and Naßmacher 2007). For example, the controversial ' $10 \mathrm{H}$ ' regulation, introduced in Bavaria in 2014 , requires any installed turbine to be a minimum distance of 10 times the turbine height from any residential building (Bayerische Bauordnung 2018). This effect of this regulation has been to substantially restrict the siting options for wind energy infrastructure.

The opportunity of private individuals and communities to participate directly in the transition by investing in renewable energy projects has been central to the successful increase in the proportion of renewable energy used in electricity generation over the last ten years. It has been estimated that $46 \%$ of installed renewable capacity was owned by farmers and private citizens in 2012 (Borchert and Wettengel 2018). However, 
changes to the Renewable Energy Act appear to have caused a drop off in co-operative investment regulations, with a transition away from feedin-tariff supports to bid or auction systems (Morris 2014). Such systems can be problematic for citizen co-operatives, which typically only plan to realise a single project and cannot therefore split the risk of a lost auction in contrast to large-scale commercial developers who can bid for several projects at once (Amalang 2016).

Although more recent signals at the Federal level clearly favour a more centralised Energiewende, the German energy transition also involves a decentralisation of energy production and the emergence of new actor networks in so-called energy regions (Gailing and Röhring 2016). Between the level of municipalities and the federal level, the formation of collaborative network-based governance is considered a determining factor for the success of regional energy transitions (Gailing 2018). An example for a bottom-up regional multi-level governance project can be found in the Oberland region in Southern Bavaria. Here, Energiewende Oberland (EWO), a civic foundation for energy transition founded in 2005, has been identified as the decisive actor responsible for institutionalising the energy transition and for building effective networks and governance structures regarding the energy sector in the region (Von Streit and Bothe, in review).

Yet despite the emergence of active regional networks (such as in the Oberland region), efforts towards a decentralised energy transition continue to meet unfavourable political and regulatory conditions set at Federal and State levels that favour a centralised Energiewende.

\section{Trends in National Household Energy Campaigns in Germany}

National household energy campaigns have primarily focused on, and prioritised technical solutions, with the primary future vision for a successful Energiewende reliant on improved technical innovation, greater energy efficiency, passive/carbon positive housing, improved energy transmission, and high-tech grid management in order to enable greater proliferation of renewables (BMWi 2018). This trend is also evident in campaigns aimed at changing energy-related behaviour. Here, the focus is firmly on encouraging individuals to make 'smarter' consumer choices in terms of more efficient lighting, heating systems and household appliances, with reduction of use strategies featuring much less prominently. A recent analysis of 60 sustainable energy consumption initiatives (SECIs) in Germany 
Table 3.1 Problem framings of 60 sustainable energy consumption initiatives from Germany

Changes in technology

20. Changes in complex interactions

‥ Changes in everyday life situations

Source Jensen et al. (2018)

(Jensen et al. 2018) closely mirrored trends in national policy, with the majority of initiatives aimed at changing technology and consumer behaviour. The continued absence of sufficiency-based strategies (e.g. the re-evaluation of necessary consumption) is a notable omission given the growing evidence of the inability of efficiency based strategies to fully achieve anticipated reductions (Druckman et al. 2011) (Table 3.1).

There is also significant stratification when it comes to particular targeted areas of energy use, with many initiatives targeting one particular aspect such as retrofitting, information campaigns targeting purchasing behaviour, saving-potential analysis, and energy or emission saving competitions. The large number of SECIs profiled demonstrates a general commitment to improving environmental awareness and the willingness to contribute to energy saving and climate protection; however, the emphasis on saving (energy and/or money) and other participatory incentives reveals that there is a current expectation that SECIs should provide 'added value' for participants.

Certain 'basics' or cultural norms around consumption would appear to be less palatable for discussion or negotiation (e.g. car ownership, holiday travel, meat consumption) and have not been targeted specifically in SECIs related to energy initiatives. This was also one of the findings of the Energiesuffizienz Project, a collaborative research initiative funded by the Federal Ministry for Education and Research. 


\section{Case Study: Energiesuffizienz Project}

The research project 'Energiesuffizienz' (energy sufficiency) was undertaken from 2013 to 2016 and was tasked with identifying the driving factors and dynamics for the expansion of energy-related 'needs' and how they could be addressed, with a view to achieving real quantitative reductions in the size and use of devices, the substitution of technical equipment in households, and the adjustment or reassessment of technical services delivered by appliances to utilities and desired by users (i.e. smart grid services) (Brischke et al. 2016). The approach concentrated on three elements: households, appliances, and urban infrastructure and services in municipalities. A criteria-based analysis was conducted that examined action and measurement options for energy sufficiency in the distinct areas of living and building, as well as individual barriers and framework conditions that influence or hinder the implementation of energy sufficiency. Based on this theoretical framework, empirical studies were carried out which employed transdisciplinary methods.

\section{Investigative Approach}

Households represented the core subjects of investigation in the project. In a representative survey of 601 households, the research team enquired as to how energy-sufficiency practices are currently perceived and evaluated, what sufficiency practices are already employed, and whether and to what extent additional sufficiency practices may be accepted in the future. For example, in the area of living space, participants were asked to rate the adequacy of their current living space ranging from 'much too small' to 'far too big'. Additionally, there were interviews with several actors at the municipal level to analyse existing measures and approaches to improve energy sufficiency. The research team used neighbourhood labs that drew on five local communities of practice (youth group, local co-op, a group of degrowth activists, senior citizens club and a Christian seniors group). The research team presented cultural probes to get to know the participants and their performances of practices also within the group, and held co-creation workshops to counter conflicts with handling sufficiency strategies. 


\section{Framing the Energy Challenge}

Brischke et al. (2016) argue that the existing policy measures that foster the Energiewende in Germany concentrate primarily on improving energy efficiency, and that they ignore energy-sufficiency strategies to a large extent. They note that while energy efficiency in many sectors has been consistently improved, total energy use has remained stable. They further note that efficiency is only one factor of total energy use, and point to the fact that the technical characteristics (size, features, etc.), use patterns and total number of appliances have a significant bearing on overall energy use. The authors further argue that energy efficiency improvements are being eaten up by higher levels of consumption and/or rising expectations of comfort. Consequently, the authors argue that as there are technical and economic limits on energy efficiency, energy sufficiency will be an important aspect in the energy transition.

In the Energiesuffizienz study, energy was framed as a consumer product that in and of itself held little interest for households in their day-to-day lives, and that energy sufficiency measures should be developed in such a way that consumers become aware of which needs and wishes are important for a high quality of life (and, conversely, which are not). Departing from traditional policy interventions that try to reduce the energy intensity of practices without questioning established consumption levels, the approach challenges this prevailing 'optimization orthodoxy' by seeking to lower demand and reduce energy use.

\section{Outcomes/Outputs}

Brischke et al. (2016) found (among other observations) that energy sufficiency practices can play a large role in efforts to reduce energy use. These sufficiency practices are already present in many households and are regarded as normal. Moreover, they are not correlated with financial endowment and can be implemented irrespective of incomes. The Energiesuffizienz Project also found that sufficiency practices are less acceptable in leisure activities than during core household duties, and that playing on people's environmental consciousness or 'guilt tripping' people into action are not necessarily helpful strategies for promoting sufficiency. Sufficiency thinking is largely incompatible with the current 
status quo, i.e. a growth-based economic system and the dominance of efficient technological fixes in sustainability thinking, policy and practice. This cannot be easily reconciled with the (more or less) radical change agenda that underpins much sufficiency thinking, i.e. that less may in fact be more (Grealis and Rau 2018).

Through open innovation workshops, the project design guide also provided detailed and specific eco-design sufficiency recommendations relating to the reduction (e.g. display and adjustability of cooling temperature, instead of an abstract scale in refrigerators and freezers), substitution (supporting the change in practices and routines towards energy and resource conservation through innovative design of the appliances, e.g. washing with low temperatures, measured laundry dosing), and adjustment of appliances (e.g. equipment should be designed such that functions and features only consume energy, when they are in use).

\section{CONCLUSION}

While early progress has been made in the area of renewable electricity generation, Germany faces significant future challenges in this area. Similarly, more sustained efforts are needed to achieve real reductions in respect of other forms of energy consumption. While Federal policy and legislation provide the overarching targets, the devolved and partially fragmented nature of energy governance in Germany and its impact on bottom-up actions by both local municipalities and civil society mean the future rate of change for the energy transition is very uncertain. Environmental consciousness and public support for the Energiewende are generally rather high. However, transition measures which fail to include citizens and local energy co-operatives may slow progress as they are more likely to meet resistance from below, especially concerning both grid development and installation of renewable energy technology. Additionally, some aspects of German culture may clash with efforts to achieve real reductions in energy consumption as part of the Energiewende. In particular, Germany's prevailing 'car culture' frequently combines with a historically influential automobile industry to undermine or weaken efforts towards a Verkehrswende (sustainable transport turn) that links closely with sustainable energy goals discussed in this chapter. The recent heated public debate in Germany concerning proposals for a speed limit of $130 \mathrm{~km}$ per hour on all German highways exemplifies this conflict. Overall, this overview has shown the need for 
future policy and change programmes that address systems of interlocking energy-related practices (e.g. mobility, space and water heating, domestic appliance use), as opposed to focusing solely on changing Germany's energy supply system from the top-down.

\section{REFERENCES}

Amalang, S. (2016). Germany's energy transition revamp stirs controversy over speed, participation. Clean Energy Wire (Online News publication). Accessed 10 January 2018 from https://www.cleanenergywire.org/dossiers/ reform-renewable-energy-act\#controversial.

Bayerische Bauordnung. (2018). Bavarian Building Regulations (BayBO) as amended on 14 August 2007 (GVBl. P. 588, BayRS 2132-1-B), most recently amended by $\$ 1$ of the Act of 10 July 2018 (GVBl. P. 523).

Borchert, L., \& Wettengel, J. (2018). Citizens' participation in the Energiewende. Clean Energy Wire (Online News publication). Accessed 10 January 2018 from https://www.cleanenergywire.org/factsheets/ citizens-participation-energiewende.

Brischke, L. A., Leuser, L., Duscha, M., Thomas, S., Thema, J., Spitzner, M., et al. (2016). Energiesuffizienz-Strategien und Instrumente für eine technische, systemische und kulturelle Transformation zur nachbaltigen Begrenzungdes Energiebedarfs im Konsumfeld Bauen/Wohnen. Heidelberg, Berlin, and Wuppertal: IFEU, Institut für Energie- und Umweltforschung Heidelberg.

Druckman, A., Chitnis, M., Sorrell, S., \& Jackson, T. (2011). Missing carbon reductions? Exploring rebound and backfire effects in UK households. Energy Policy, 39(6), 3572-3581.

EEA. (2019). National Inventory Report of German greenhouse gas inventory 1990-2017. Accessed 21 January 2019 from http://cdr.eionet.europa.eu/ $\mathrm{de} / \mathrm{eu} / \mathrm{mmr} / \mathrm{art} 07$ inventory/ghg_inventory/envxd4xlg/2019-01-15_EU_ NIR_2019.pdf.

Eurostat. (2018a). Share of final energy consumption in the residential sector by type of end-use, 2016. Accessed 9 January 2019 from https://ec.europa.eu/ eurostat/statistics-explained/index.php?title=Energy_consumption_in_ households\#Data_sources_and_availabilityEurostat.

Eurostat. (2018b). Share of fuels in the final energy consumption in the residential sector, 2016 ( $n r g \_110 a$ ). Updated 31 May 2018.

Eurostat. (2019a). Distribution of households by household type from 2003 onwards-EU-SILC survey (ilc_lvph02). Updated 19 January 2019.

Eurostat. (2019b). Distribution of population by degree of urbanisation, dwelling type and income group-EU-SILC survey (ilc_lvho01). Updated 19 January 2019. 
Eurostat. (2019c). Distribution of population by tenure status, type of household and income group-EU-SILC survey (ilc_lvho02). Updated 19 January 2019.

Federal Association of Energy and Water Industry (BDEW). (2018). Energy demand by demand group 2017. https://www.bdew.de/media/documents/ Nettostromverbrauch-nach-Verbrauchergruppen-2017_online_o_jaehrlich_ Ki_27042018.pdf.

Federal Ministry for Economic Affairs and Energy (BMWi). (2015). The energy of the future: Fourth "energy transition” Monitoring Report-Summary. Berlin, Germany. Accessed on 17 January 2019.

Federal Ministry for Economic Affairs and Energy (BMWi). (2018). Unsere Energiewende: sicher, sauber, bezablbar. Accessed 27 January 2019 from https://www.bmwi.de/Redaktion/EN/Dossier/energy-transition.html.

Federal Ministry for Justice and Consumer Protection (BMJV). (2017). Ordinance implementing the law on the ecodesign of energy-related products (EVPGV) amended 18 January 2017 (BGBl. I S. 85).

Federal Ministry for Justice and Consumer Protection (BMJV). (2018). Renewable Energy Sources Act amended 17 December 2018.

Fraunhofer Institute. (2018). Power generation in Germany-Assessment of 2017. Accessed 27 January 2019 from www.energy-charts.de.

Gailing, L. (2018). Die räumliche Governance der Energiewende: Eine Systematisierung der relevanten Governance-Formen. In O. Kühne \& F. Weber (Eds.), Bausteine der Energiewende (pp. 75-90). Wiesbaden: Springer Fachmedien Wiesbaden.

Gailing, L., \& Röhring, A. (2016). Is it all about collaborative governance? Alternative ways of understanding the success of energy regions. Utilities Policy, 41, 237-245.

Grealis, E., \& Rau, H. (2018). Exploring the (in)compatibilities of efficiency and sufficiency thinking in the context of efforts to reduce domestic energy use. Third International Conference of the Sustainable Consumption Research and Action Initiative (SCORAI): Sustainable Consumption: Fostering Good Practices and Confronting the Challenges of the 21 st Century. Copenhagen.

IEA. (2014). Electric power consumption ( $k W h$ per capita). Accessed 27 January 2019 from http://data.worldbank.org/indicator/EG.USE.ELEC. KH.PC? end =2014\&locations=DE-IE-FR-FI-GB-DK-LV-LT-HR-CZ-ITSE - E S - S I - S K - RO - P L - PT - MT - N L - LU - H U - GR - E E - CY - B G - AT BE\&start $=2014 \&$ wiew $=$ bar.

Jensen, C. L., Goggins, G., Fahy, F., Grealis, E., Vadovics, E., Genus, A., \& Rau, H. (2018). Towards a practice-theoretical classification of sustainable energy consumption initiatives: Insights from social scientific energy research in 30 European countries. Energy Research \& Social Science, 45, 297-306. 
Morris, C. (2014). Bundestag adopts new rules for renewables. Energie Transition: The Global Energiewende. Accessed 20 January 2019 from https://energytransition.org/2014/07/bundestag-adopts-new-renewable-energy-act/.

Naßmacher, H., \& Naßmacher, K.-H. (2007). Kommunalpolitik in Deutschland. Wiesbaden: Springer.

Renewable Energy Act. (2014). (EEG) (Federal Law Gazette I p. 1066), last amended by Article 1 of the Act of 17 December 2018 (BGBI. I P. 2549).

Renn, O., \& Marshall, J. P. (2016). Coal, nuclear and renewable energy policies in Germany: From the 1950s to the "Energiewende". Energy Policy, 99, 224-232.

Von Streit, A., \& Bothe, J. (in review). Institutional work and spatial practices within regional transitions towards renewable energies: Experiences from southern Germany.

Open Access This chapter is licensed under the terms of the Creative Commons Attribution 4.0 International License (http://creativecommons.org/licenses/ by $/ 4.0 /$ ), which permits use, sharing, adaptation, distribution and reproduction in any medium or format, as long as you give appropriate credit to the original author(s) and the source, provide a link to the Creative Commons license and indicate if changes were made.

The images or other third party material in this chapter are included in the chapter's Creative Commons license, unless indicated otherwise in a credit line to the material. If material is not included in the chapter's Creative Commons license and your intended use is not permitted by statutory regulation or exceeds the permitted use, you will need to obtain permission directly from the copyright holder.

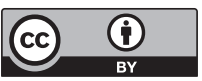

